\title{
Methods to perform systematic reviews of patient preferences: a literature survey
}

\author{
Tsung Yu* (D), Nomin Enkh-Amgalan and Ganchimeg Zorigt
}

\begin{abstract}
Background: Systematic reviews are a commonly used research design in the medical field to synthesize study findings. At present-although several systematic reviews of patient preference studies are published-there is no clear guidance available for researchers to conduct this type of systematic review. The aim of our study was to learn the most current practice of conducting these systematic reviews by conducting a survey of the literature regarding reviews of quantitative patient preference studies.

Methods: Our survey included systematic reviews of studies that used a stated quantitative preference design to elicit patient preferences. We identified eligible reviews through a search of the PubMed database. Two investigators with knowledge of the design of patient preference studies independently screened the titles and abstracts, and where needed, screened the full-text of the reviews to determine eligibility. We developed and pilottested a form to extract data on the methods used in each systematic review.

Results: Our search and screening identified 29 eligible reviews. A large proportion of the reviews $(19 / 29,66 \%)$ were published in 2014 or after; among them, nine reviews were published in 2016. The median number of databases searched for preference studies was four (interquartile range $=2$ to 7 ). We found that less than half of the reviews (13/ $29,45 \%)$ clearly reported assessing risk of bias or the methodological quality of the included preference studies; not a single review was able to perform quantitative synthesis (meta-analysis) of the data on patient preferences.
\end{abstract}

Conclusion: These results suggest that several methodological issues of performing systematic reviews of patient preferences are not yet fully addressed by research and that the methodology may require future development.

Keywords: Patient preference, Systematic review, Meta-analysis

\section{Background}

Making healthcare decisions is difficult since multidimensional factors are often involved. For example, when patients are in the situation to choose treatments for their conditions, they may need to jointly consider factors such as the benefits, harms, costs and inconveniences of each treatment in order to choose their most "preferred" option. Some patients are more concerned about the side effects of treatments; others may be more risk-tolerant. Thus, learning about patient preference information-or the "assessments of the relative desirability or acceptability to patients of specified alternatives" [1]-is critical in making an informed and patientcentered decision. It becomes even more important when

\footnotetext{
* Correspondence: tsung.yu.cmu@gmail.com

Department of Public Health, China Medical University, No 91 Hsueh-Shih Road, Taichung, Taiwan
}

multiple options exist, especially when it is unclear which option is superior or when the preferences vary considerably between patients [2].

Many regulatory agencies and health technology assessment bodies have also recognized the importance of studying patient preferences to improve their decisionmaking [3, 4]. Patient preference information can be elicited in qualitative studies such as patient interviews and focus groups. Or, it can be elicited quantitatively from a population of patients using the "stated preference" approaches developed mostly in the health economics field, including designs such as the rating scale, standard gamble, time trade-off or discrete choice experiment $[5,6]$. In the end, individual patients may make their choices based on their own circumstances (socio-demographics, disease severity, comorbidities, or financial situations) and their own preferences. However, 
to make decisions such as drug approvals or reimbursement at a population level, preferences elicited from a survey of population can be beneficial to the decisionmaking for the entire population [7].

A systematic approach to studying patient preferences seems valuable. First, we need to conduct more preference-eliciting surveys and then do it across different populations to capture the heterogeneity, if such heterogeneity exists. When multiple preference-eliciting studies are done, a systematic review of these studies may then be needed to synthesize and summarize the study findings. Although several systematic reviews of patient preference studies are published, at present no standard guidance is available yet for researchers to conduct this type of systematic review.

Recently some efforts have been devoted to developing these review methodologies. For example, Yepes-Nuñez et al. [8] have done a systematic survey of patient preference reviews to identify items that previous reviewers have used in making risk of bias assessment of primary studies addressing preferences. They then grouped these items into seven domains for assessing the risk of bias, such as the instrument health state presentation. Besides risk of bias assessment, review methodologies for searches of preference studies, or qualitative and quantitative synthesis of primary study results are also highly needed from reviewers to conduct a preference review, which would be much different from that for a regular intervention review. Therefore, our goal was to gain an overview of the most current methods and practice that have been reported in the literature for conducting systematic reviews of quantitative patient preference studies.

\section{Methods}

\section{Selection of studies}

Our approach was not to perform a full systematic review of reviews, but rather to do a literature survey of systematic reviews. We focused on the methodology used by reviewers to conduct research synthesis of evidence on quantitative patient preferences. We restricted our selection of systematic reviews to the PubMed database. We adapted existing search filters $[9,10]$ and developed a strategy for the PubMed database with two concepts for the search: "systematic review" and "patient preferences" ((search[tiab] OR meta-analysis[pt] OR MEDLINE[tiab] OR (systematic[tiab] AND review[tiab])) AND ("patient preference" [mh] OR preference[ti] OR preferences[ti]])). The search was performed on December 1, 2016.

Our pre-specified study inclusion criterion was any systematic review that aimed to synthesize quantitative evidence of patient preferences for attributes of an intervention or a health technology. This included medications, surgeries, medical devices, behavioral interventions, diagnostic tests and screening programs. The eligible systematic review had to include some studies using a quantitative stated preference design to assess patient preferences (such as the rating scale, visual analogue scale, standard gamble, time trade-off, contingent valuation, discrete choice experiment, or best-worst scaling). We excluded reviews that focused only on qualitative research. In some preference studies, participants were only asked to make choices between alternatives (for example, Drug A vs. Drug B) but the attributes of these alternatives (for example, benefits, harms, costs, and inconveniences) were not explicitly stated. We did not include reviews that focused only on this type of studies since they did not generate evidence on quantitative patient preferences for any attributes of an intervention or a health technology. Only English articles were included in our sample.

Two investigators with knowledge on the design of patient preference studies independently screened the list of search results to assess study eligibility by reviewing titles and abstracts. Where the reviewers could not make decisions on eligibility based on titles and abstracts alone, the full-text of each systematic review was downloaded and examined. Disagreement on the study eligibility was resolved through group discussion.

\section{Data extraction and analysis}

We developed and pilot-tested a data extraction form for this survey. The main items in the form included the following: objectives and conclusions of the systematic review, the criteria used to include/exclude patient preference studies, the methods used to search for preference studies, the methods used to assess the quality of preference studies, and the qualitative or quantitative methods used to synthesize study findings. One experienced reviewer independently performed the data extraction and assessment of methodology; another reviewer reviewed and checked the answers to each item in the form. Disagreement between the two reviewers was resolved by group discussion. We summarized these results in the tables of study characteristics.

\section{Results \\ Search results}

We identified 495 records from the search of the PubMed database. After title/abstract screening, 449 records were excluded, leaving 46 records. We excluded 17 records after full-text screening; the reasons for exclusion can be found in the Fig. 1. Most of the records were excluded because they focused on studies that assessed the preferences for alternatives (e.g., Drug A vs. Drug B) but the attributes of these alternatives were not explicitly stated in their assessment. Finally, we included 29 records (systematic reviews) in this literature survey. 


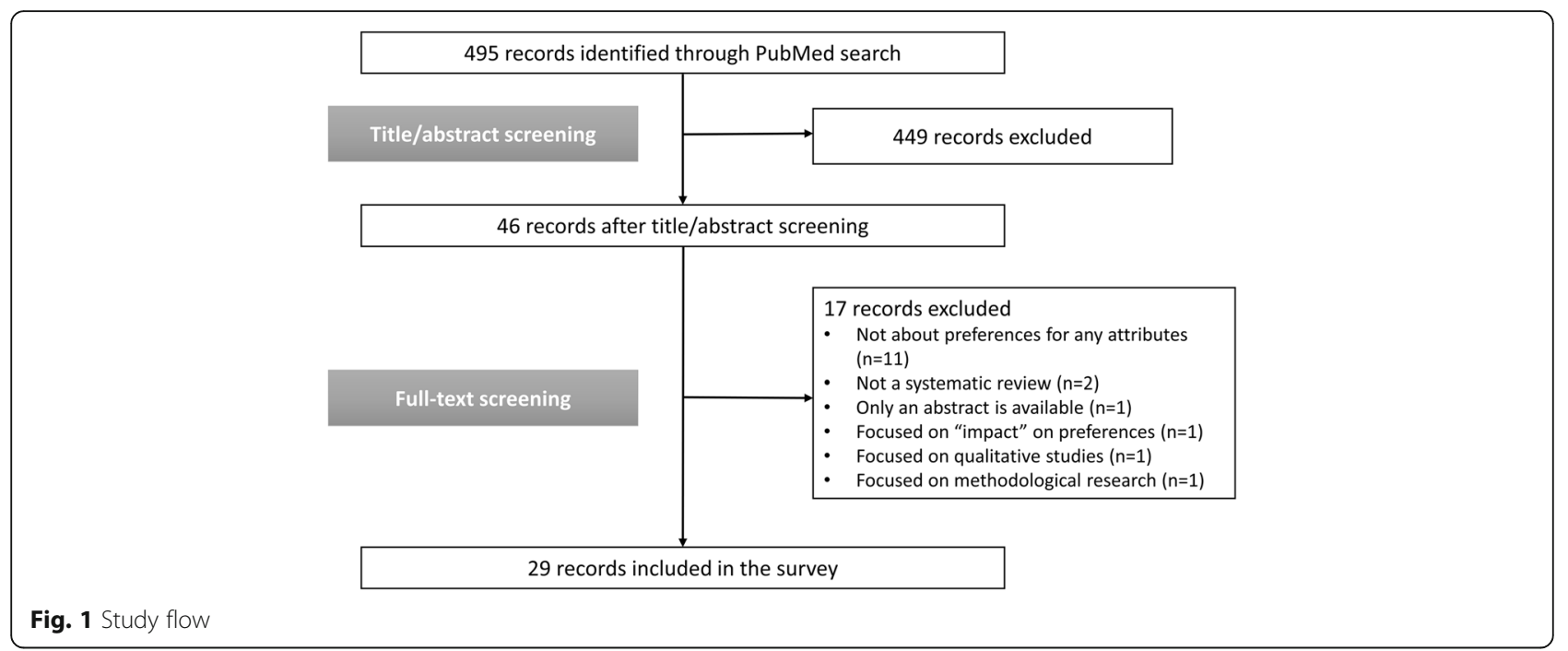

\section{Characteristics of included reviews}

Table 1 lists the 29 included systematic reviews [10-38]. The number of . About two-thirds (19/29) of the reviews were published in 2014 or after; among them, 9 reviews were published in 2016. About half of the included reviews were on cancers (14/29); three were on psoriasis; three were on type 2 diabetes; two were on attentiondeficit/hyperactivity disorder, and the remaining seven reviews were each about different diseases. Among reviews on cancers $(n=14), 11$ were studying the preferences for cancer treatment and three were studying preferences for cancer screening.

Table 2 shows the characteristics of these 29 included reviews. The median number of databases searched was four (interquartile range $=2$ to 7 ). Six reviews $(6 / 29$, $21 \%)$ searched one database; four reviews $(4 / 29,14 \%)$ searched two; eleven reviews $(11 / 29,38 \%)$ searched three to five and eight reviews $(8 / 29,28 \%)$ searched more than five. All reviews $(n=29)$ searched for studies through PubMed or MEDLINE, 19/29 (66\%) through EMBASE, 9/29 (31\%) through CINAHL, 9/29 (31\%) through PsycINFO, and 8/29 (28\%) through EconLit. Almost half of the reviews $(14 / 29,48 \%)$ searched reference lists of the included studies. Few reviews searched for non-English articles $(7 / 29,24 \%)$ or for conference abstract/unpublished studies/grey literature $(6 / 29,21 \%)$. The search strategies used in each review to identify studies of patient preferences are summarized in Table 3 . The terms developed by these reviews are focused mainly on "patient preferences" and the name of the study design used to elicit patient preferences.

Most reviews $(25 / 29,86 \%)$ documented the methods used to assess study eligibility, for example, by mentioning the double and independent screening of title/abstract/full-text. Less than half of the reviews (13/29, $45 \%$ ) clearly reported assessing the risk of bias or the methodological quality of the included preference studies. None of the reviews were able to perform quantitative synthesis (meta-analysis) of the preference data. The types of patient preference study design included in each review-such as the rating scale, visual analogue scale, standard gamble, time trade-off, contingent valuation, discrete choice experiment, and best-worst scaling-are listed in Table 4. A wide range of preference study designs is often included in this type of systematic reviews. Almost half of the reviews $(14 / 29,48 \%)$ were fully or partly funded by government, and 9/29 (31\%) were funded by industry (see Table 2).

\section{Discussion}

Our survey of the medical literature shows that there has been an increase in systematic reviews on patient preferences being published since 2014. This may suggest an increasing interest in conducting preferenceeliciting studies, as well as systematic reviews of these studies. Almost half of the included reviews were on cancers, suggesting the strong interest from cancer researchers or their need to synthesize patient preference data. Although a number of this type of systematic reviews are published, many methodological issues regarding performing these systematic reviews are not yet fully addressed by previous research. For example, there is a lack of clear guidance or consensus on the approaches to searching for preference studies, to assessing methodological quality of preference studies, or to quantitatively synthesizing the data from preference studies.

Systematic reviews are a commonly used research design in the medical field to synthesize study findings-such as the treatment's benefits, harms or costs-in order to inform evidence-based decisionmaking. Not only can systematic reviews summarize study results, they can also serve as a way to examine the 
Table 1 Included systematic reviews

\begin{tabular}{lll}
\hline First author & Year & Title \\
\hline Belinchón [11] & 2016 & $\begin{array}{l}\text { Adherence, satisfaction \& preferences } \\
\text { for treatment in patients with psoriasis } \\
\text { in the European Union: a systematic } \\
\text { review of the literature }\end{array}$ \\
Bereza [12] & 2015 & $\begin{array}{l}\text { Patient preferences in severe COPD \& } \\
\text { asthma: a comprehensive literature } \\
\text { review }\end{array}$ \\
Blanchard [13] 2016 & $\begin{array}{l}\text { Assessing head \& neck cancer patient } \\
\text { preferences \& expectations: a } \\
\text { systematic review }\end{array}$ \\
Blinman [14] 2010 & $\begin{array}{l}\text { Patients' preferences for chemotherapy } \\
\text { in non-small-cell lung cancer: a } \\
\text { systematic review } \\
\text { Bradley [15] }\end{array}$ & $\begin{array}{l}\text { Review of patterns of practice \& } \\
\text { patients' preferences in the treatment } \\
\text { of bone metastases with palliative } \\
\text { radiotherapy }\end{array}$ \\
Brooker [16] & 2013 & $\begin{array}{l}\text { Quantitative patient preference } \\
\text { evidence for health technology } \\
\text { assessment: a case study }\end{array}$ \\
Currie [17] & 2014 & $\begin{array}{l}\text { A systematic review of patient preference } \\
\text { elicitation methods in the treatment of } \\
\text { colorectal cancer } \\
\text { Preferences of colorectal cancer patients } \\
\text { for treatment \& decision-making: a systematic } \\
\text { literature review }\end{array}$ \\
\hline Damm [18] & 2014
\end{tabular}
Eek [19] 2016 Patient-reported preferences for oral vs. intravenous administration for the treatment of cancer: a review of the literature

Eiring [20] 2015 What matters to patients? A systematic review of preferences for medication associated outcomes in mental disorders

Emberton [21] $2010 \quad$ Medical treatment of benign prostatic hyperplasia: physician \& patient preferences \& satisfaction

Gutknecht [22] 2016 A systematic review on methods used to evaluate patient preferences in psoriasis treatments

Hamelinck [23] 2014 Patients' preferences for surgical \& adjuvant systemic treatment in early breast cancer: a systematic review

\section{Objective \\ "To examine \& describe the current literature on patient preferences, satisfaction \& adherence to treatment for psoriasis in the European Union." \\ "To summarize original research articles determining patient preference in moderate-to-severe disease." [COPD \& asthma]}

"We conducted a systematic review of the current evidence regarding the preferences \& priorities of patients with head \& neck cancer."

"To find, evaluate \& summarise studies quantifying the survival benefits that cancer patients judged sufficient to make chemotherapy for NSCLC worthwhile."

"To review the patterns of practice among radiation oncologists \& patients' preferences in the treatment of bone metastases with palliative radiotherapy."

"To explore the feasibility \& desirability of incorporating patient preferences within the health technology assessment process by working through a case study." [COPD]

"To assess the use of patient preference in colorectal cancer treatment."

"To identify the preferences of CRC patients with regard to treatment preferences \& involvement in the decision-making process regarding treatment choices."

"To evaluate the administration preferences of cancer patients, specifically between oral \& intravenous treatment, as well as the factors contributing to preference."

"To investigate patients' preferences for outcomes associated with psychoactive medications."

“This review evaluates patients' \& physicians' preferred treatment options for managing BPH \& patient satisfaction with therapy."

"To give an overview of methods that have been used in international published studies to evaluate patient preferences in psoriasis treatments."

"To give an overview of patient self-reported factors affecting preferences for breast conserving surgery vs. mastectomy, the minimal benefit patients require from adjuvant chemotherapy or adjuvant hormonal therapy to consider it worthwhile, \& factors influencing this minimally-required benefit."

"To identify \& assess the literature reporting on the treatment preferences of adult patients with type 2 diabetes."

"To investigate patients' values \& preferences regarding aortic valve replacement therapy for aortic stenosis."

catheter or surgical aortic valve replacement therapy for aortic stenosis: a systematic review

MacLean [26] 2012 Patient values \& preferences in decision making for antithrombotic therapy: a systematic review

Mansfield [27] 2016 Stated preference for cancer screening: a systematic review of the literature,
"We conducted a systematic review relating to values \& preferences of patients considering antithrombotic therapy."

"We reviewed stated-preference studies for breast, cervical, \& colorectal cancer screening to identify the
Date of search

Dec. 2014

Nov. 2014

Sept. 2016

June 2006

March 2011

March 2014

Sept. 2012

Jan. 2015

Sept. 2013

June 2008

Dec. 2014

Oct. 2012

Jan. 2013

Unclear

Sept. 2009

July 2013 
Table 1 Included systematic reviews (Continued)

\begin{tabular}{|c|c|c|c|c|}
\hline First author & Year & Title & Objective & Date of searc \\
\hline & & 1990-2013 & $\begin{array}{l}\text { types of attributes included, the use of questions to } \\
\text { assess uptake, \& whether gaps exist in these areas." }\end{array}$ & \\
\hline Phillips [28] & 2006 & $\begin{array}{l}\text { A review of studies examining stated } \\
\text { preferences for cancer screening }\end{array}$ & $\begin{array}{l}\text { "To conduct a systematic review of stated preference } \\
\text { studies for cancer screening, identify gaps in the literature, } \\
\& \text { determine which types of research should be conducted } \\
\text { in the future." }\end{array}$ & May 2005 \\
\hline Purnell [29] & 2014 & $\begin{array}{l}\text { Patient preferences for noninsulin } \\
\text { diabetes medications: a systematic review }\end{array}$ & $\begin{array}{l}\text { "To systematically review patient preferences for } \\
\text { noninsulin diabetes medications in adults with } \\
\text { type } 2 \text { diabetes." }\end{array}$ & Jan. 2013 \\
\hline Sadique [30] & 2011 & $\begin{array}{l}\text { Women's preferences regarding options } \\
\text { for management of atypical, borderline } \\
\text { or low-grade cervical cytological } \\
\text { abnormalities: a review of the evidence }\end{array}$ & $\begin{array}{l}\text { "To identify empirical studies evaluating women's } \\
\text { preferences regarding alternative management } \\
\text { pathways \& to compare the impact of alternative } \\
\text { elicitation methods on results." }\end{array}$ & March 2009 \\
\hline Schatz [31] & 2015 & $\begin{array}{l}\text { Systematic review of patients' \& parents' } \\
\text { preferences for ADHD treatment options } \\
\& \text { processes of care }\end{array}$ & $\begin{array}{l}\text { "To synthesize reports across existing DCE, BWS, } \\
\text { TTO, \& SGI studies to assess which aspects of ADHD } \\
\text { treatment are most studied as well as most preferred } \\
\text { \& influential in treatment decisions." }\end{array}$ & Oct. 2014 \\
\hline Schmidt [32] & 2016 & $\begin{array}{l}\text { Preferences of lung cancer patients for } \\
\text { treatment \& decision-making: a } \\
\text { systematic literature review }\end{array}$ & $\begin{array}{l}\text { "To identify the preferences of lung cancer patients } \\
\text { with regard to their treatment \& involvement in the } \\
\text { decision-making process." }\end{array}$ & Sept. 2012 \\
\hline Showalter [33] & 2015 & $\begin{array}{l}\text { Factors that influence patient preferences } \\
\text { for prostate cancer management options: } \\
\text { a systematic review }\end{array}$ & $\begin{array}{l}\text { "We performed a systematic review to evaluate } \\
\text { evidence regarding factors that influence patient } \\
\text { preferences for management options for localized } \\
\text { prostate cancer." }\end{array}$ & April 2014 \\
\hline Stewart [34] & 2016 & $\begin{array}{l}\text { Preference for pharmaceutical } \\
\text { formulation \& treatment process } \\
\text { attributes }\end{array}$ & $\begin{array}{l}\text { "To examine studies on preferences for pharmaceutical } \\
\text { treatment process attributes, focusing on research in } \\
\text { diabetes, oncology, osteoporosis, \& autoimmune disorders." }\end{array}$ & Oct. 2013 \\
\hline Umar [35] & 2012 & $\begin{array}{l}\text { Elicitation \& use of patients' preferences } \\
\text { in the treatment of psoriasis: a systematic } \\
\text { review }\end{array}$ & $\begin{array}{l}\text { "To critically review the scientific evidence regarding } \\
\text { the elicitation \& use of patients' preferences in } \\
\text { psoriasis treatment." }\end{array}$ & Nov. 2009 \\
\hline Van Brunt [10] & 2011 & $\begin{array}{l}\text { Preferences related to attention-deficit } \\
\text { /hyperactivity disorder \& its treatment }\end{array}$ & $\begin{array}{l}\text { "To identify \& summarize published research on } \\
\text { preferences related ADHD \& its treatment, while } \\
\text { suggesting directions for future research." }\end{array}$ & Unclear \\
\hline Von Arx [36] & 2014 & $\begin{array}{l}\text { The patient perspective of diabetes care: } \\
\text { a systematic review of stated preference } \\
\text { research }\end{array}$ & $\begin{array}{l}\text { "To examine how stated preference methods are } \\
\text { applied in diabetes care, \& to evaluate the value } \\
\text { of this information in developing the patient } \\
\text { perspective in clinical \& policy decisions." }\end{array}$ & May 2013 \\
\hline Wilke [37] & 2016 & $\begin{array}{l}\text { Patient preferences for oral anti- } \\
\text { coagulation therapy in atrial fibrillation: } \\
\text { a systematic literature review }\end{array}$ & $\begin{array}{l}\text { "To systematically analyse the scientific literature } \\
\text { assessing the preferences of AF patients with regard } \\
\text { to long-term oral anticoagulant treatment." }\end{array}$ & 2015 \\
\hline Wortley [38] & 2014 & $\begin{array}{l}\text { Assessing stated preferences for } \\
\text { colorectal cancer screening: a critical } \\
\text { systematic review of discrete choice } \\
\text { experiments }\end{array}$ & $\begin{array}{l}\text { "To undertake a systematic review of discrete choice } \\
\text { experiments of CRC screening." }\end{array}$ & April 2013 \\
\hline
\end{tabular}

ADHD Attention-deficit/hyperactivity disorder, $A F$ Atrial fibrillation, $B P H$ Benign prostatic hyperplasia, BWS Best-worst scaling, COPD Chronic obstructive pulmonary disease, CRC Colorectal cancer, DCE Discrete choice experiment, NSCLC Non-small-cell lung cancer, SGI Standard gamble interview, TTO Time trade-off

heterogeneity in different studies or to identify the subgroups for which their results differ from others. There is a potentially large heterogeneity in the findings across patient preference studies, even for those addressing similar questions, because different researchers may use different preference designs, include different items for patients to assign preferences, and on top of that, sociodemographics are known to have great influences on preferences $[39,40]$. Therefore, in many situations, systematic reviews may be a useful and necessary way to not only study patient preferences, but at the same time to also deal with these very heterogeneous studies, which poses great challenges to systematic reviewers.

Building up a comprehensive search strategy is one of the most important steps to conducting a systematic review. A comprehensive search strategy will identify as far as possible all relevant studies addressing the research question of interest, which can involve searching in different electronic databases, searching reference lists of included studies, searching for non-English articles, and searching for conference abstracts, unpublished studies or grey literature. 
Table 2 Characteristics of the systematic reviews

\begin{tabular}{|c|c|}
\hline Characteristics of the systematic review $(N=29)$ & \\
\hline \multicolumn{2}{|l|}{ Number of databases searched } \\
\hline One, n (\%) & $6(21)$ \\
\hline Two, $n(\%)$ & $4(14)$ \\
\hline Three to five, $n$ (\%) & $11(38)$ \\
\hline More than five, $n(\%)$ & $8(28)$ \\
\hline \multicolumn{2}{|l|}{ Database searched } \\
\hline PubMed or MEDLINE, n (\%) & $29(100)$ \\
\hline EMBASE, $n$ (\%) & $19(66)$ \\
\hline CINAHL, $n(\%)$ & $9(31)$ \\
\hline PsycINFO, n (\%) & $9(31)$ \\
\hline EconLit, $n(\%)$ & $8(28)$ \\
\hline Other databases, $n$ (\%) & $14(48)$ \\
\hline Searched for non-English articles, n (\%) & $7(24)$ \\
\hline Reported searching reference lists of included studies, n (\%) & $14(48)$ \\
\hline $\begin{array}{l}\text { Reported searching for conference abstracts, unpublished } \\
\text { studies or grey literature, } \mathrm{n}(\%)\end{array}$ & $6(21)$ \\
\hline Reported methods used to assess study eligibility, n (\%) & $25(86)$ \\
\hline $\begin{array}{l}\text { Reported assessing risk of bias or methodological quality of } \\
\text { included studies, } \mathrm{n}(\%)\end{array}$ & $13(45)$ \\
\hline $\begin{array}{l}\text { Used quantitative methods (meta-analysis) to synthesize } \\
\text { study data, } \mathrm{n}(\%)\end{array}$ & $0(0)$ \\
\hline \multicolumn{2}{|l|}{ Funding sources listed } \\
\hline No funding, $n(\%)$ & $3(10)$ \\
\hline Government, $n(\%)$ & $14(48)$ \\
\hline Industry, n (\%) & $9(31)$ \\
\hline Others, n (\%) & $5(17)$ \\
\hline Unclear, n (\%) & $2(7)$ \\
\hline
\end{tabular}

In our survey, most reviews had searched in databases beyond the PubMed/ MEDLINE database (median number of databases searched: 4), but only one-fifth to one-fourth of the reviews had searched for non-English articles (24\%) or had searched for conference abstracts, unpublished studies or grey literature (21\%). A few methodological questions regarding the search for patient preference studies are still not answered and deserve our attention. For example, are some of the databases such as EconLit (a database focusing on economics publications) required for searching for patient preference studies? Are preference data reported in conference abstracts useful to systematic reviewers? Is searching for non-English articles important? We need more methodological research to address these questions in order to support us in doing a comprehensive search, while at the same time not being lost in the literature. Also, we found that there was a wide range of search terms used by systematic reviewers to retrieve patient preference studies. This indicates the variety of terms used by most investigators to describe patient preferences and a need for search filters. Some groups have developed search filters for preference studies [41, 42], and more research on these search filters is needed to test for their validity.

Another issue we identified in our survey of reviews was that less than half of the studies reported assessing risk of bias or the methodological quality of patient preference studies. Methods to assess study quality/risk of bias of randomized controlled trials, for example, are mature because lots of research efforts have been dedicated to developing assessment tools for this. In our survey, some reviewers such as Purnell and colleagues adapted other existing tools or constructed checklists themselves when they were appraising the study quality [29]. They assessed whether the preference study had properly addressed purposes, respondents, explanation, findings, and significance. Others such as the U.S. Food and Drug Administration also listed several quality standards for patient preference studies in one of their guides [2] and researchers from McMaster University have generated 23 items for assessing the risk of bias in preference studies [8]. Implementing the methodological quality assessment tools for patient preference studies in actual practice would be challenging since there are so many different types of study designs available. We need more research to develop a standard way that can be used by most systematic reviewers to appraise the quality of preference studies.

In a systematic review of randomized controlled trials, meta-analyses (quantitative synthesis) are performed to synthesize data in order to generate more precise estimates. When it is difficult or not reasonable to combine study data, systematic reviewers may choose not to perform a meta-analysis. We found in our survey that no review was able to perform a meta-analysis of patient preferences, because for instance some preference studies may use a visual analogue scale approach and report preference weight ranging from zero to a hundred; some studies may conduct a discrete choice experiment and report coefficients from a conditional logistic regression model. Moreover, these studies may include very heterogeneous patient populations and the items included for preference assessment can vary greatly from study to study. We noticed that there are a few reviews using tables to summarize the preference rankings of the attributes obtained within each study, which helps authors better communicate with readers [29, 36]. Perhaps statistics such as the frequency of an item being ranked as most important could be used as a measure in meta-analysis to synthesize preference data. We need more statisticians and methodologists in this field to develop novel approaches to doing metaanalysis in preference research. 
Table 3 Search strategies used for patient preferences

\begin{tabular}{|c|c|}
\hline Review & Strategy used to search for preference studies \\
\hline Belinchón, 2016 & Search terms included "preferences" and "utility". \\
\hline Bereza, 2015 & Search terms included "preference" and "utilities". \\
\hline Blanchard, 2016 & $\begin{array}{l}\text { Search terms included "patient preference", "patient priorities" and the different patient } \\
\text { stated-preference methods, such as "rating", "ranking", "best-worst", "self-explicated", } \\
\text { "value-based conjoint analysis", "rating-based conjoint analysis", "choice-based conjoint } \\
\text { analysis", "take it or leave it", "tradeoff" and "trade-off". }\end{array}$ \\
\hline Blinman, 2010 & Search terms included "preference", "utility", "attitude", "expectation" and "willingness". \\
\hline Bradley, 2007 & Search terms included "patient preferences", "patient satisfaction" and "patient participation". \\
\hline Brooker, 2013 & $\begin{array}{l}\text { Search terms included those that relate to "patient perspectives", "satisfaction", "preferences" } \\
\text { and "values". }\end{array}$ \\
\hline Currie, 2014 & $\begin{array}{l}\text { Search terms included those that relate to existing patient preference elicitation methodologies: } \\
\text { "patient preference", "shared decision-making", "patient involvement", "patient participation", } \\
\text { "patient satisfaction", "physician-patient relation", "standard gamble", "time trade-off", "willingness } \\
\text { to trade", "willingness to pay", "decision board" and "discrete choice experiment". }\end{array}$ \\
\hline Damm, 2014 & Search terms included "patient" and "preference or willingness". \\
\hline Eek, 2016 & Search terms included "preference", "prefer", "preferred", "choice", "select" and "selection". \\
\hline Eiring, 2015 & Comprehensive search strategies were developed (see http://bmjopen.bmj.com/content/5/4/e007848). \\
\hline Emberton, 2010 & Search terms included "patient preference", "perception" and "satisfaction". \\
\hline Gutknecht, 2016 & $\begin{array}{l}\text { Search terms included keywords of preference methods in health economics: "preferences", " } \\
\text { conjoint analysis", "choice model", "discrete choice", "DCE", "decision analysis", "multi-criteria decision } \\
\text { analysis", "MCDA", "multi-attribute utility", "analytic hierarchy process", "AHP", "trade-off", "best-worst } \\
\text { scaling", "willingness-to-pay", "WTP", "willingness to accept", "contingent valuation" and } \\
\text { "standard gamble". }\end{array}$ \\
\hline
\end{tabular}

Search terms included "patient preference", "choice", "decision", "choice behavior", "decision making" and "patient satisfaction".

Joy, 2013

Search terms included "conjoint analysis", "satisfaction", "choice model", "stated preference",

"discrete choice", "DCE", "decision analysis", "preferences", "multicriteria decision analysis", "MCDA",

"multi-attribute utility", "analytic hierarchy process", "trade off", "self-explicated", "best-worst scaling",

"utilities", "preference weight", "willingness to pay", "WTP", "willingness to accept", "contingent valuation", "priorities" and "valuation".

Lytvyn, 2016

Search terms included "health utility", "patient values", "patient preferences" and "health-related quality of life".

Unclear

Mansfield, 2016

Search terms included "conjoint analysis", "discrete choice", "discrete ranking" and "discrete rank".

Phillips, 2006

Search terms included "patient satisfaction", "numerical data", "consumer satisfaction", "health knowledge", "attitudes", "practice", "choice behavior", "conjoint analysis", "contingent valuation", "stated preference", "discrete choice" and "willingness to pay".

Purnell, 2014

Search terms included methods to assess patient preferences (e.g., "conjoint analysis", "decision analysis", "utilities", and "stated preferences").

Sadique, 2011

Search terms included "preferences", "values", "willingness-to-pay" and "utility".

Schatz, 2015

Schmidt, 2016

Showalter, 2015

Search terms included "patient preferences", "stated preferences", "discrete choice", "conjoint analysis", "best worst", "maximum difference", "standard gamble", "time trade-off" and "utility values".

Search terms included "patient", "preference", and "willingness".

Search terms included "conjoint analysis", "satisfaction", "choice model", "stated preference", "discrete choice", "DCE", "decision analysis", "preferences", "multi-criteria decision analysis", "MCDA",

"multi-attribute utility", "analytic hierarchy process", "trade off", "self-explicated", "best-worst scaling", "utilities", "preference weight", "willingness to pay", "WTP", "willingness to accept", "contingent valuation", "priorities" and "valuation".

Stewart, 2016

Search terms included "stated preference(s)", "time trade-off", "standard gamble", "conjoint", "contingent valuation", "discrete choice" and "willingness-to-pay".

Umar, 2012

Van Brunt, 2011

Search terms included "patient preferences", "shared decision-making", "patient involvement", "patient participation", "patient satisfaction" and "physician-patient relation".

Search terms included "health state utility", "utility", "discrete choice", "standard gamble", "time trade-off", "quality-adjusted life year", "conjoint analysis", "patient preference", "preference", "prefer", "satisfaction", "acceptability", "decision" and "choice". 
Table 3 Search strategies used for patient preferences (Continued)

\begin{tabular}{ll}
\hline Review & Strategy used to search for preference studies \\
\hline Wilke, 2016 & $\begin{array}{l}\text { Search terms included "discrete choice experiment", "treatment preference", "conjoint" } \\
\text { and "trade off". }\end{array}$ \\
Wortley, 2014 & Search terms included "stated preference" and "choice experiment". \\
\hline
\end{tabular}

A reporting guideline for patient preference studies is likely to substantially improve the reporting of such studies. We found that systematic reviewers in our survey often needed to include terms such as "utility," "attitude," "expectation," "willingness," "satisfaction," and "value" to capture relevant publications, indicating that the definitions and terms used

Table 4 Types of included preference studies

\begin{tabular}{|c|c|}
\hline Review & $\begin{array}{l}\text { Type of included preference studies } \\
\text { reported by the review }\end{array}$ \\
\hline Belinchón, 2016 & CA, DCE \\
\hline Bereza, 2015 & WTP \\
\hline Blanchard, 2016 & RS, SG, TTO, VAS \\
\hline Blinman, 2010 & Preference study design not specified \\
\hline Bradley, 2007 & Preference study design not specified \\
\hline Brooker, 2013 & Preference study design not specified \\
\hline Currie, 2014 & DCE, SG, TTO \\
\hline Damm, 2014 & CA, DCE, RS, SG, TTO \\
\hline Eek, 2016 & CA \\
\hline Eiring, 2015 & CA, DCE, PC, RS, SG, TTO, VAS, WTP \\
\hline Emberton, 2010 & DCE, RS \\
\hline Gutknecht, 2016 & CA, DCE, RS, SG, TTO, VAS, WTP \\
\hline Hamelinck, 2014 & Preference study design not specified \\
\hline Joy, 2013 & CA, CV, RS, SG, TTO, WTP \\
\hline Lytvyn, 2016 & SG \\
\hline MacLean, 2012 & PTOT, RS, SG, TTO, VAS \\
\hline Mansfield, 2016 & CA, DCE \\
\hline Phillips, 2006 & $C A, C V$ \\
\hline Purnell, 2014 & CA, DCE, RS, SG, TTO, VAS, WTP \\
\hline Sadique, 2011 & SG, WTP \\
\hline Schatz, 2015 & BWS, DCE, SG \\
\hline Schmidt, 2016 & CV, DCE, RS, WTP \\
\hline Showalter, 2015 & DCE, TTO \\
\hline Stewart, 2016 & BWS, CV, DCE, SG, TTO, WTP \\
\hline Umar, 2012 & DCE, PTO, SG, TTO, VAS, WTP \\
\hline Van Brunt, 2011 & DCE, SG \\
\hline Von Arx, 2014 & $C V, D C E$ \\
\hline Wilke, 2016 & CA, DCE, PTO, SG, TTO, VAS \\
\hline Wortley, 2014 & DCE \\
\hline
\end{tabular}

BWS Best-worst scaling, CA Conjoint analysis, CV Contingent valuation, DCE Discrete choice experiment, $P C$ Pairwise comparison, PTO Person trade-off, PTOT Probability trade-off technique, RS Ranking or rating scale, SG Standard gamble, TTO Time trade-off, VAS Visual analogue scale, WTP Willingness to pay by most investigators for patient preferences may be at present quite inconsistent. Additionally, in several reviews we found that their included studies did not refer to themselves as the specific design for preference-eliciting research (such as visual analogue scale, time trade-off, or discrete choice experiment); instead the investigators described the studies as a cross-sectional survey or patient questionnaire research, which made it more difficult for systematic reviewers to conduct the search. Reviewers rely heavily on the reporting of published articles to perform assessment and synthesis of studies. Only if there is a complete, clear and transparent reporting of the original articles can most systematic reviewer conduct proper evidence synthesis [43]. Similar to having other reporting guidelines, having a guideline on reporting of patient preference studies may indirectly improve the design and conduct of the primary studies as well. We hope in the near future that such guidance is available to investigators aiming to embark on patient preference research.

The major limitation of this work is that we did not conduct a complete systematic review of reviews. We are somewhat limited in our search of the literature since we did not perform the search beyond the PubMed database, did not explode our search terms extensively, and did not search for non-English publications. This could have made us miss some high-quality systematic reviews-although this is not likely to be the case.

\section{Conclusion}

Our survey of the literature demonstrates that there is a strong interest in the healthcare field in conducting research on patient preferences and also on performing systematic reviews of patient preference studies. However, our survey also reveals that there is still room for improvement of the reporting of patient preference studies. Likewise, many methodologies used to perform systematic reviews of these studies need to be tested and refined by researchers as well. In particular, research community should develop research agenda to inform systematic reviewers working on patient preferences of the search for studies, quality assessment of studies, synthesis of studies and reporting of reviews.

\section{Acknowledgments}

We thank Ms. Yu-Lin Huang for her help on data extraction. 


\section{Funding}

Funding was partly provided by the Ministry of Science and Technology, Taiwan (grant number MOST 106-2314-B-039-001) and China Medical University, Taiwan (grant number CMU106-N-17).

\section{Availability of data and materials}

Data analyzed in this study are available upon request.

\section{Authors' contributions}

TY conceived the study idea and drafted the manuscript with support from NEA and GZ. All authors conducted the data extraction. All authors contributed to the interpretation of the results, and reviewed and approved the final manuscript.

\section{Ethics approval and consent to participate}

Not applicable.

\section{Consent for publication}

Not applicable.

\section{Competing interests}

The authors declare that they have no competing interests.

\section{Publisher's Note}

Springer Nature remains neutral with regard to jurisdictional claims in published maps and institutional affiliations.

Received: 17 May 2017 Accepted: 27 November 2017 Published online: 11 December 2017

\section{References}

1. Ho M, et al. A framework for incorporating patient preferences regarding benefits and risks into regulatory assessment of medical technologies. Value Health. 2016;19(6):746-50.

2. US Food and Drug Administration. Patient preference information voluntary submission, review in premarket approval applications, humanitarian device exemption applications, and de novo requests, and inclusion in decision summaries and device labeling, issued August 2016. (https://www.fda.gov/downloads/MedicalDevices/ DeviceRegulationandGuidance/GuidanceDocuments/UCM446680.pdf).

3. European Medicines Agency. The Patient's Voice in the Evaluation of Medicines: How Patients Can Contribute to Assessment of Benefit and Risk, issued October 2013. (http://www.ema.europa.eu/docs/en_GB/document library/Report/2013/10/WC500153276.pdf)

4. Danner $\mathrm{M}$, et al. Integrating patients' views into health technology assessment: analytic hierarchy process (HAP) as a method to elicit patient preferences. Int J Technol Assess Health Care. 2011:27(4):369-75.

5. Drummond MF, Sculpher MJ, Claxton K, Stoddart GL, Torrance GW. Methods for the economic evaluation of health care programmes: Oxford university press; 2015.

6. Brett Hauber A, Fairchild AO, Reed Johnson F. Quantifying benefit-risk preferences for medical interventions: an overview of a growing empirical literature. Appl Health Econ Health Policy. 2013;11(4):319-29.

7. US Food and Drug Administration. Factors to consider when making benefit risk determinations in medical device premarket approval and de NovoClassifications, issued August. 2016. https:/www.fda.gov/ucm/groups/ fdagov-public/@fdagov-meddev-gen/documents/document/ucm517504.pdf.

8. Yepes-Nuñez JJ, et al. Forty-two systematic reviews generated 23 items for assessing the risk of bias in values and preferences' studies. J Clin Epidemiol. 2017:85:21-31

9. Montori VM, et al. Optimal search strategies for retrieving systematic reviews from Medline: analytical survey. BMJ. 2005:330(7482):68.

10. Van Brunt $K$, et al. Preferences related to attention-deficit/hyperactivity disorder and its treatment. Patient Prefer Adherence. 2011;5:33-43.

11. Belinchon I, et al. Adherence, satisfaction and preferences for treatment in patients with psoriasis in the European Union: a systematic review of the literature. Patient Prefer Adherence. 2016:10:2357-67.

12. Bereza BG, et al. Patient preferences in severe COPD and asthma: a comprehensive literature review. Int J Chron Obstruct Pulmon Dis. 2015;10: 739-44
13. Blanchard $P$, et al. Assessing head and neck cancer patient preferences and expectations: a systematic review. Oral Oncol. 2016:62:44-53.

14. Blinman $P$, et al. Patients' preferences for chemotherapy in non-small-cell lung cancer: a systematic review. Lung Cancer. 2010;69(2):141-7.

15. Bradley NM, et al. Review of patterns of practice and patients' preferences in the treatment of bone metastases with palliative radiotherapy. Support Care Cancer. 2007;15(4):373-85.

16. Brooker AS, et al. Quantitative patient preference evidence for health technology assessment: a case study. Int J Technol Assess Health Care. 2013; 29(3):290-300.

17. Currie A, et al. A systematic review of patient preference elicitation methods in the treatment of colorectal cancer. Color Dis. 2015;17(1):17-25.

18. Damm K, Vogel A, Prenzler A. Preferences of colorectal cancer patients for treatment and decision-making: a systematic literature review. Eur J Cancer Care (Engl). 2014;23(6):762-72.

19. Eek $D$, et al. Patient-reported preferences for oral versus intravenous administration for the treatment of cancer: a review of the literature. Patient Prefer Adherence. 2016;10:1609-21.

20. Eiring $\mathrm{O}$, et al. What matters to patients? A systematic review of preferences for medication-associated outcomes in mental disorders. BMJ Open. 2015; 5(4):e007848.

21. Emberton M. Medical treatment of benign prostatic hyperplasia: physician and patient preferences and satisfaction. Int J Clin Pract. 2010;64(10):1425-35.

22. Gutknecht $M$, et al. A systematic review on methods used to evaluate patient preferences in psoriasis treatments. J Eur Acad Dermatol Venereol. 2016;30(9):1454-64

23. Hamelinck VC, et al. Patients' preferences for surgical and adjuvant systemic treatment in early breast cancer: a systematic review. Cancer Treat Rev. 2014;40(8):1005-18.

24. Joy SM, et al. Patient preferences for the treatment of type 2 diabetes: a scoping review. PharmacoEconomics. 2013;31(10):877-92.

25. Lytvyn $L$, et al. Patient values and preferences on transcatheter or surgical aortic valve replacement therapy for aortic stenosis: a systematic review. BMJ Open. 2016:6(9):e014327.

26. MacLean $\mathrm{S}$, et al. Patient values and preferences in decision making for antithrombotic therapy: a systematic review: antithrombotic therapy and prevention of thrombosis, 9th ed: American College of Chest Physicians Evidence-Based Clinical Practice Guidelines. Chest. 2012;141(2 Suppl): e1S-23S.

27. Mansfield C, et al. Stated preference for cancer screening: a systematic review of the literature, 1990-2013. Prev Chronic Dis. 2016:13·E27.

28. Phillips KA, et al. A review of studies examining stated preferences for cancer screening. Prev Chronic Dis. 2006:3(3):A75.

29. Purnell TS, et al. Patient preferences for noninsulin diabetes medications: a systematic review. Diabetes Care. 2014;37(7):2055-62

30. Sadique MZ, Legood R. Women's preferences regarding options for management of atypical, borderline or low-grade cervical cytological abnormalities: a review of the evidence. Cytopathology. 2012;23(3):161-6.

31. Schatz NK, et al. Systematic review of Patients' and Parents' preferences for ADHD treatment options and processes of care. Patient. 2015;8(6):483-97.

32. Schmidt $K$, et al. Preferences of lung cancer patients for treatment and decision-making: a systematic literature review. Eur J Cancer Care (Engl). 2016:25(4):580-91.

33. Showalter TN, Mishra MV, Bridges JF. Factors that influence patient preferences for prostate cancer management options: a systematic review. Patient Prefer Adherence. 2015;9:899-911.

34. Stewart KD, et al. Preference for pharmaceutical formulation and treatment process attributes. Patient Prefer Adherence. 2016;10:1385-99.

35. Umar $\mathrm{N}$, et al. Elicitation and use of patients' preferences in the treatment of psoriasis: a systematic review. Acta Derm Venereol. 2012;92(4):341-6.

36. von Arx LB, Kjeer T. The patient perspective of diabetes care: a systematic review of stated preference research. Patient. 2014;7(3):283-300.

37. Wilke $\mathrm{T}$, et al. Patient preferences for oral anticoagulation therapy in atrial fibrillation: a systematic literature review. Patient. 2017:10(1):17-37.

38. Wortley S, et al. Assessing stated preferences for colorectal cancer screening: a critical systematic review of discrete choice experiments. Patient. 2014;7(3):271-82

39. Constantinescu $\mathrm{F}$, et al. Understanding why rheumatoid arthritis patient treatment preferences differ by race. Arthritis Rheum. 2009;61(4):413-8.

40. Veldwijk J, et al. Preferences for vaccination: does health literacy make a difference? Med Decis Mak. 2015;35(8):948-58. 
41. van Hoorn $\mathrm{R}$, et al. The development of PubMed search strategies for patient preferences for treatment outcomes. BMC Med Res Methodol. 2016;16:88.

42. Selva A SI, Zhang Y, Sanabria AJ, Pequeño S, Rigau D, Martínez L, et al. Development of a search strategy for studies about patients' values and preferences. In: Evidence-Informed Public Health: Opportunities and Challenges. Abstracts of the 22nd Cochrane Colloquium; 2014 21-26 Sep; Hyderabad, India John Wiley \& Sons; 2014.

43. Schulz KF, Altman DG, Moher D. CONSORT 2010 statement: updated guidelines for reporting parallel group randomised trials. BMC Med. 2010;8:18.

Submit your next manuscript to BioMed Central and we will help you at every step:

- We accept pre-submission inquiries

- Our selector tool helps you to find the most relevant journal

- We provide round the clock customer support

- Convenient online submission

- Thorough peer review

- Inclusion in PubMed and all major indexing services

- Maximum visibility for your research

Submit your manuscript at www.biomedcentral.com/submit 